\title{
MORE ON SOME HARDY TYPE INTEGRAL INEQUALITIES
}

\section{BANYAT SROYSANG}

Abstract. In 2012, W. T. Sulaiman presented new kinds of Hardy's integral inequalities. In this paper, we derive some new extensions of the famous Hardy's integral inequality. The results present direct generalization of the original Hardy inequality. In addition, the corresponding reverse relation is also obtained.

Mathematics subject classification (2010): 26D15.

Keywords and phrases: Hardy's integral inequality, Hölder's inequality.

\section{REFERENCES}

[1] G. H. HARDY, Notes on a theorem of Hilbert, Math. Z., 6 (1920), 314-317.

[2] N. Levinson, Generalizations of inequalities of Hardy and Littlewood, Duke Math. J., 31 (1964), 389-394.

[3] W. T. Sulaiman, Some Hardy type integral inequalities, Appl. Math. Lett., 25 (2012), 520-525. 